were distended with dark blood; there was no evidence of any endocarditis, pericarditis, or congenital malformation. Both lungs showed emphysema, chronic congestion, nedema, and partial collapse. There in the right pleura. The liver was "nutmeggy" and the spleen was of the firm "cardiac" type. The kidneys were somewhat large and apparently not diseased.

CASE 5 (1904).-Man, aged 42 years, a Russian Jew. Apparently a somewhat similar case to Case 4, but, unfortunately, no blood count was made. During the last days of life there was a semi-comatose condition, apparently due to chronic carbonic acid poisoning. The history was that for about the last four years of life the patient,
man, had suffered from cough and respiratory trouble.

i'ecropsy.-The heart (weight 13 oz.) showed dilatation and hypertrophy of the right side. Both the lungs were more or less adherent to the chest walls; there was a good deal of chronic interstitial fibrosis,
and some obsolete remnants of tubereulosis were noted. The liver, and some obsolete remnants of tubereulosis were noted. The liver,
spleen, and kidneys showed chronic congestion. The mucous memspleen, and kidneys showed chronic congestion. The mucous membrane of the stomach and small intestine was engorged with blood, intestine contained slightly altered blood, as if bleeding from the engorged mucous membrane had occurred a little before death.

CASE 6 (1906).-Man, aged 59 years, strongly built. At about the age of 29 years he had commenced to suffer from shortness of breath (asthma?), which he himself attributed to the practice of "coitus increased and there had been occasional exacerbations. From the age of 14 years he had been a cigarette-smoker, smoking 8 to 10 cigarettes a day. No history of alcohol or syphilis. On admission (Dec. 29th, 1906) the patient had the physical signs of pulmonary emphysema and bronchitis; there were dry and moist bronchitic sounds. Dyspnoea, orthopncea, cyanosis. No fever. The liver was somewhat enlarged and there seemed to be a little ascites. The fingers were "clubbed." The urine (diminished in quantity) was free from albumin and sugar. There was muco-purulent expectoration, free from tubercle bacilli. The brachial systolic blood pressure was $105-110 \mathrm{~mm}$. Hg. The capillary blood from a finger showed great polycythamia; the red cells millimetre of blood; the hremoglobin (by Haldane's method) was 115 per cent. Under treatment by rest in bed, small doses of potassium iodide and tincture of lobelia, Guy's pills, oxygen In the second week of February, when he left the hospital, there was In the second week of February, when he left the hospital, there was
still some crepitation over the lower portions of the lungs and there still some crepitation over the lower portions of the lungs and there
was some muco-purulent expectoration. Respiration about 21 ; pulse was some muco-purulent expectoration. Respiration about 21 ; pulse
about 100 . The radial arteries felt decidedly thickened and somewhat tortuous, but the brachial systolic blood pressure was rather low (about tortuous, but the brachial systolic blood pressure was rather low (about
$115 \mathrm{~mm} . \mathrm{Hg}$ ). The liver was apparently no longer enlarged. The $115 \mathrm{~mm} . \mathrm{Hg}$ ). The liver was apparently no longer enlarged. The
amount of urine was rather above the average. The red cells numbered amount of urine was rather above the average. The red cells numbered lost much of their congested appearance. The improvement, however, did not last long.

CASE 7 (1910).-Man, aged 35 years, who for the last seven years before admission had been subject to "asthmatic" attacks. In the hospital there was great eyanosis, with dyspncen, some "clubbing" of fingers and toes, and slight oedema of the feet and the lower part of the body. There was crepitation over the lower portions of the lungs. The heart was enlarged to the right, and there was an apical systolic murmur and a double murmur at the base. The liver was enlarged and there was slight ascites. The urine contained a trace of albumin. Brachial systolic blood pressure $110 \mathrm{~mm}$. Hg. Blood examination (Dr. Dorner, Nov. 28th, 1910): Hrmoglobin (by Sahli's method), 135 per cent.; red cells, 7,683,300 in the cubic millimetre of blood; white cells, 9500 . The coagulation time (by Sir A. E. Wright's coagulometer) was 10 minutes. According to Determann's clinical viscosimeter the blood viscosity was greatly above the normal. The patient became less cyanotic, but was cied a month after admission.

Necropsy. - The heart (weight $16 \mathrm{oz}$.) showed great hypertrophy of the Vecropsy.- The heart (weight $16 \mathrm{oz}$.) showed great hypertrophy of the
right side, so that the two sides were nearly similar in appearance. The right side, so that the two sides were nearly similar in appearance. The
mitral valve showed old thickening and retraction and slight recent mitral valve showed old thickening and retraction and slight recent
vegetations. Both pleure were almost universally adherent and both vegetations. Both pleure were almost universally adherent and both lungs were emphysematous. There were some embolic infarctions in the right lung and some chronic fibrosis of the upper part of the left spleen small and tirm, of the "cardiac type." All the viscera were greatly congested.

CASE 8 (1904).-Married woman, aged 33 years. I am indebted to $m y$ colleague, Dr. Karl Fiirth, for his kind permission to quote this case. There was some evidence pointing to previous indulgence in alcohol. showed polycyt mich the hæmoglobin was about 130 per cent, the showed polycythæmia. The hæmoglobin was about 130 per cent.; the
red cells numberer about $7,000,000$ and the white cells about 11,000 to the cubic millimetre of blood. There were crepitations over the lungs. the cubic millimetre of blood. There were crepitations over the lungs. A cardiac sistoli murmur was best heard betreen the apex and the
sternum. The edge of the licer could be felt reaching to below the sternum. The edge of the licer could be felt reaching to below the umbilical level. The spleen seemed also to be enlarged. but the edge could not be felt. The urine, diminished in quantity, showed a little
albumin and a few tube casts. Ascites developed, and also a suffocative pulmonary condition, which was followed by coma (probably a result of carbonic acid poisoning). A moderate venesection (about $10 \mathrm{oz}$.) did little, if any, good.

Necropsy. The heart (weight $17 \mathrm{oz}$.) was hypertrophied, chiefly on the right side. Both tricuspid and mitral orifices were dilated, and the free borders of both these valves appeared somewhat thickened.
Both lungs showed emphysema, bronchitis, and congestion, and (by microscopic examination) a certain amount of chronic indurative pneumonia. There were pleuritic acthesions on both sides, which could, however, be separated. The liver (weight $88 \mathrm{oz}$.) was "nutmeggy," and the spleen (weight 16 oz.) was enlarged and (by microscopic examination) much congested. The kidneys (weight together $16 \mathrm{oz}$. were rather large and (microscopically) showed passive congestion. CASE 9 (1906). -Man, aged 28 years. For about the last nine years he had been subjeet to attaeks of asthma, which at first recurred every two or three weeks, afterwards more frequently. Of late, however, he had had no regular attack, but continuous shortness of breath. In the enlargement of the liver, ascites, ceoema, and slight albuminuria
There were crepitations at the base of both lungs, and a systolic murmur at the apex of the heart. Blood examination (NoF. 29th, 1906): Hæmoglobin (by Haldane's method), 115 per cent. ; red cells, had improved during a first stay in the hospital (March-April, 1906) but did not do well when readmitted in November, 1906. He died in December, 1906

Necropsy. - The heart showed much hypertrophy and dilatation of the right side; the wall of the hypertrophied right ventricle was almost equal in size to that of the left ventricle. The lungs were emphysematous and the dependent portions were much congested. The liver was the "cardiac type."

CASE 10 (1904).-Woman, aged 22 years, rather fat and plethoriclooking. She was under the care of my colleague, Dr. Furth, who has kindly allowed me to mention it. There was a history of previous The liver was much enlarged. The urine was free from albumin and The liver was much enlarged. The urine was free from albumin and
sugar. The red cells numbered $6,500,000$ in the cubic mlllimetre of sugar.

CASE 11 (1910).-Man, aged 48 years, fat and plethoric-looking, whose illness was said to have commenced six weeks previously with dyspnoea and cough. The venesection blood contained about $6,200,000$ red cells to the cubic millimetre, and its viscosity value (as estimated by
Determann's clinical viscosimeter) was about $8 \cdot 3$ times that of water (both at $20^{\circ} \mathrm{C}$.). The case was, however, complicated by nephritis and high bloo pressure (the brachial systolic blood pressure was 200 mm. Hg). I am not sure whether it really belonged to the present Harley-street, W.

\section{DIFFICULT LABOUR CAUSED BY FETAL ASCITES.}

BY S. GORDON LUKER, M.D. CANTAB., OBSTETRIC TUTOR AND REGTSTRAR, LONDON HOSPITAL.

THE patient, a i.-para aged 27, was sent to the London Hospital in the second stage of labour with a history that the fotal head had been pulled off during attempts at delivery. On examination the general condition of the patient was good. The abdomen was large; the uterus up to the ensiform. Per vaginam, the os was fully dilated, the neck and arms of the fœtus presenting; the fœtal abdomen was enormously distended and cystic, preventing delivery. The condition of foetal ascites was diagnosed.

An anæsthetic was given and the fotal abdomen was opened with scissors. Clear fluid was poured out, and after the first gush (three pints at least) six pints were collected. A small fotus was easily delivered. The fœtus was a small male, its length (without head) being $30 \mathrm{~cm}$. The abdomen was enormously distended, and it was clear that the fluid came from the peritoneal cavity. The bladder was much distended and thickened; its upper margin was $3 \frac{1}{3}$ inches above the pubis, nearly up to the umbilicus. It contained a. little urine, a drop of which could be expressed with diffculty from the penis. A urethral stricture was encountered near the entrance to the bladder on attempting to pass a bristle per urethram. Both ureters were much dilated; they were in places 1 inch in diameter. The kidneys appeared normal. The liver and the other abdominal viscera appeared normal.

Microscopically a section of the abdominal wall showed chronic inflammation of the peritoneum.

Examination of the footal asoitic Auid.-Report by Dr. P. N. Panton: "Reaction alkaline. Specific gravity, 1010. Urea absent. No reducing substance present. Proteids present in large amount, the majority being proteoses, the minority. coagulable proteid."

According to Ballantyne, ${ }^{1}$ examination of the ascitic fluid in similar cases has rarely been carried out; in two cases albumin was found, but there was no mention of proteose.

Previous health and history of patient. - One child, female, 11 months old, alive and well. Previous pregnancy, labour and puerperium normal. No serious iliness previously. Wassermann reaction negative. Urine acid, 1022; urea, 1.67 per cent.; albumin, a trace; no sugar. At the onset of labour the patient thought she was nine months pregnant; for some months she had had some pain and discomfort in the abdomen, and had noticed she was more prominent than during her last pregnancy.

The case was under the care of Dr. R. Drummond Maxwell. The patient was delivered by Mr. G. E. Neligan, resident accoucheur.

Margaret-street, $\mathrm{w}$. 